\title{
Prevalence of 15 Mitochondrial DNA Mutations Among Type 2 Diabetic Patients with or without Clinical Characteristics of Maternally Inherited Diabetes and Deafness
}

clinical case report

DAISY CRISPIM

Aline A. F. Estivalet

ISRAEL ROISENBERG

JORGE L. GROSS

LUIS H. CANANI

Endocrinology Division, Hospital de Clinicas de Porto Alegre, Universidade Federal do Rio

Grande do Sul (DC, AAFE, JLG, LHC); Genetics Department,

Universidade Federal do Rio Grande do Sul (IR); Porto Alegre, RS, Brazil.
Received in 25/8/2008

Accepted in 23/9/2008
The aim of the present study is to investigate the prevalence of ten described mitochondrial DNA (mtDNA) mutations in patients with type 2 diabetes, and search for new mutations in four mtDNA genes in a subgroup of patients with characteristics of maternally inherited diabetes and deafness (MIDD). These mutations were investigated in 407 type 2 diabetic patients without characteristics of mitochondrial diabetes ("classical" type 2 diabetes group) and in 38 type 2 diabetic patients with characteristics suggestive of MIDD. Through sequencing of four mtDNA genes in MIDD patients, we selected five others potentially pathogenic mutations that were also screened in the remaining patients. Overall, the frequency of the fifteen analyzed mutations was $36.84 \%$ in the MIDD group and $2.45 \%$ in the "classical" type 2 diabetes group ( $p<$ 0.001 ). In conclusion, our study reinforces the importance of mtDNA mutations in the pathogenesis of MIDD. (Arq Bras Endocrinol Metab 2008; 52/8:1228-1235)

Keywords: Type 2 diabetes; Mitochondrial DNA mutations; Mitochondrial diabetes; MIDD; A3243G tRNA ${ }^{\text {Leu(UUR) }}$ mutation

\section{RESUMO}

Prevalência de 15 Mutações no DNA Mitocondrial entre Pacientes Diabéticos Tipo 2 com ou sem Características Clínicas de Diabetes e Surdez Herdados Maternalmente.

Os objetivos deste estudo foram investigar a prevalência de dez mutações conhecidas no DNA mitocondrial (mtDNA) em pacientes com diabetes tipo 2, e procurar por novas mutações em quatro genes mitocondriais em um subgrupo de pacientes com características de MIDD (Maternally Inherited Diabetes and Deafness). Estas mutações foram investigadas em 407 pacientes diabéticos tipo 2 sem características de diabetes mitocondrial (grupo de diabetes tipo 2 clássico) e em 38 pacientes com diabetes tipo 2 e com características sugestivas de MIDD. Através do seqüenciamento de quatro genes mitocondriais nos pacientes com MIDD, selecionou-se cinco outras mutações potencialmente patogênicas que também foram investigadas no restante dos pacientes. De uma forma geral, a freqüência total das 15 mutações analisadas foi de $36,8 \%$ no grupo de pacientes com MIDD e de $2,4 \%$ no grupo de diabetes tipo 2 clássico ( $p<0,001)$. Em conclusão, nosso estudo reforça a importância de mutações mitocondriais na patogênese do MIDD. (Arq Bras Endocrinol Metab 2008; 52/8:1228-1235)

Descritores: Diabetes tipo 2; Mutações no DNA mitocondrial; Diabetes mitocondrial; MIDD; Mutação A3243G no tRNALeu(UUR) 
ype 2 diabetes mellitus (DM) seems to be mater-

nally transmitted in several families, possibly linked to the maternal mitochondrial inheritance in humans $(1,2)$. Mitochondrial genes are plausible causative agents for DM, since mitochondrial oxidative phosphorylation (OXPHOS) plays an important role in glucose-stimulated insulin secretion from beta cells (3). The most commonly reported mitochondrial DNA (mtDNA) mutation associated with DM is the A3243G mutation in the tRNA ${ }^{\mathrm{Leu}(\mathrm{UUR})}$ gene. This mutation was first described in association with the MELAS syndrome (encephalomyopathy, lactic acidosis, and stroke-like episodes syndrome) (4), and was more recently recognized as a cause of maternally inherited diabetes and deafness (MIDD) (5). In addition to the maternal inheritance and association with progressive neurosensorial deafness, MIDD has the following characteristics: it tends to develop during middle age (20-40 years), to occur in non-obese subjects, to frequently require patients to undergo insulin therapy because of the progressive insulin secretory defect, to be complicated by other mitochondrial disorders, and to account for 1-2\% of the unselected diabetic population $(6,7)$.

Recently, there have been several reports on the occurrence of over 40 different mtDNA mutations in families with maternal DM $(1,8)$. Nevertheless, the prevalence of several of these mutations in the type 2 diabetic population is still unknown. The aim of the present study is to investigate the prevalence of 10 previously described mtDNA mutations in a type 2 diabetic group from Southern Brazil, and also search for new mutations in $4 \mathrm{mtDNA}$ genes in a subgroup of diabetic patients with characteristics of maternally inherited diabetes and deafness (MIDD).

\section{SUBJECTS AND METHODS}

\section{Pacients}

This study was carried out on 445 unrelated type 2 diabetic patients (344 Caucasoid- and 101 African-Brazilians) who are participating in a multicenter study in the Brazilian State of Rio Grande do Sul. Type 2 DM was diagnosed according to the World Health Organization criteria (9). Written informed consent was obtained from all subjects and the study was approved by the Hospitals' Ethical Committees.

Thirty-eight patients with characteristics of MIDD were identified from the type 2 diabetic group. The criteria of inclusion in the MIDD group were clear evi- dence of maternal transmission of type $2 \mathrm{DM}$ (presence of DM in the mother and/or other maternal relatives in three consecutive generations or through two consecutive generations with at least three affected individuals) plus two or more of the following features: neurosensorial deafness; age at onset $<40$ years; body mass index $(\mathrm{BMI})<25 \mathrm{~kg} / \mathrm{m}^{2}$; short stature $(<1.5 \mathrm{~m}$ for women and $<1.6 \mathrm{~m}$ for men); low levels of C-peptide and/or use of insulin therapy; and presence of some previously diagnosed mitochondrial disorder, for example, MELAS; neurosensorial deafness; mitochondrial myopathy and myoclonus epilepsy with ragged red fibers (MERRF); encephalomyopathy; hypertrophic cardiomyopathy; and Leber's hereditary optic neuropathy (LHON) syndrome $(1,10)$.

All patients underwent a standardized clinical and laboratory evaluation. Hypertension was considered to be present when blood pressure was $>140 / 90 \mathrm{mmHg}$, or if the patient was taking antihypertensive drugs. Weight and height were used to calculate BMI (kg/ $\mathrm{m}^{2}$ ). Diabetic retinopathy was assessed by ophthalmoscopic examination. The renal status was based on the albumin excretion rate (AER) in at least two out of three consecutive 24-h timed collections. Patients were classified as having diabetic nephropathy if the AER $\geq$ $20 \mu \mathrm{g} / \mathrm{min}$. The diagnosis of distal sensory neuropathy was based on abnormal results of Achilles tendon reflexes, vibration or sensory perception. Audiometry was performed by a specialized technician and used to assess the sensorineural status in $62.5 \%(n=15)$ of the subjects carrying mtDNA mutations.

Blood glucose was determined using the glucose oxidase method; serum creatinine by the Jaffé reaction; glycohemoblobin $(\mathrm{GHb})$ by an ion-exchange HPLC (Merck-Hitachi L-9100 GhB Analyser, reference range: 4.7-6.0\%); total plasma cholesterol and triglycerides by enzymatic methods; urinary albumin concentration by immunoturbidimetry (Sera-Pak immuno microalbuminuria, Bayer, Tarrytown, NY), and C-peptide levels by radioimmunoassay (Diagnostic System Laboratories Incorporation, Webster, USA).

\section{Genotypic analyses and direct sequencing}

DNA was extracted from peripheral blood samples. We investigated the presence of 10 previously described mtDNA mutations using PCR-RFLP analyses (Cl310T, Al438G, A3243G, T3271C, G3316A, T3394C, A8344G, Al2026G, Tl4577C and Tl4709C). Restriction products were separated on polyacrilamide gels stained with ethidium bromide (homoplasmic mutations) or silver (heteroplasmic mutations). Subjects 
with mtDNA mutations had their genotype confirmed by direct sequencing in a MegaBace 1000 (GE HealthCare, UK) system.

We used direct sequencing to search for new mutations in two mtDNA fragments in patients with characteristics suggestive of MIDD. For the fragment containing the tRNA ${ }^{\mathrm{Leu}(\mathrm{UUR})}$ gene, $\mathrm{NADH}$-dehydrogenase subunit 1 (NDl) gene and part of the 16S-rRNA gene, we utilized primers corresponding to positions L3150-3169 and H4369-4350 of the mtDNA and also the internal primers L3705-3726 and H3791-3770. For the fragment containing the tRNA ${ }^{\text {Lys }}$ gene, ATPase8 gene and part of the ATPase 6 gene, we used the primers spanning the positions L8199-8218 and H8627-8608. These genes were selected because most mtDNA mutations previously reported to be associated with mitochondrial diabetes occur around these regions $(1,8)$.

Confirmation of those mutations that were not previously described as polymorphisms was performed by sequencing in the reverse direction on independent PCR products. Previous descriptions and evaluations of the sequence variations were searched for in the MITOMAP database or in the Human Mitochondrial Genome Database $(\mathrm{mtDB})(11,12)$. In Table l, we present the localization of the mutations screened in type 2 diabetic patients as well as the nature of these mutations (heteroplasmy or homoplasmy), the amino-acid changed, and the primers and restriction enzymes utilized.

\section{Statistical analyses}

Data are presented as means \pm SD or percentage (n). Mutation frequencies in type 2 diabetic patients with or without characteristics of MIDD were compared using $\chi^{2}$ or Fisher's exact test. Clinical and laboratory characteristics were compared by unpaired Student's t-test or $\chi^{2}$, as appropriate. Variables with skewed distribution were logarithmically transformed before analyses and are presented as geometric mean (range). In all cases, a two-tailed probability value of $\mathrm{p}<0.05$ was considered significant. All statistical analyses were performed using the SPSS version 14.0 (SPSS, Chicago, IL).

Table 1. List of mtDNA mutations analyzed in the present study and methods of detection.

\begin{tabular}{|c|c|c|c|c|c|c|}
\hline Mutation & Gene & $\begin{array}{l}\text { Amino-acid } \\
\text { change }\end{array}$ & Nature & Primers & Enzyme & Ref. ${ }^{b}$ \\
\hline C1310T & 12S-rRNA & - & Homoplasmic & L1279-1298/H1510-1491 & Rsal & - \\
\hline A1438G & 12S-rRNA & - & Homoplasmic & L1413-1437a/H1539-1518 & Trull & - \\
\hline A3243G & tRNALeu (UUR) & - & Heteroplasmic & L3029-3048/H3456-3437 & Apal & 39 \\
\hline T3271C & tRNALeu (UUR) & - & Heteroplasmic & L3029-3048/H3456-3437 & Affll & 40 \\
\hline G3316A & ND1 & Ala/Thr & Homoplasmic & L3029-3048/H3456-3437 & Haelll & 39 \\
\hline T3394C & ND1 & Tyr/His & Homoplasmic & L3029-3048/H3456-3437 & Haelll & 39 \\
\hline T3548C & ND1 & Ile/Thr & Heteroplasmic & L3433-3454/H3571-3549a & Taql & - \\
\hline A8344G & tRNALys & - & Heteroplasmic & L8278-8305/H8386-8336a & Bgll & 41 \\
\hline A8348G & tRNALys & - & Homoplasmic & L8197-8221/H8349-8373a & Rsal & - \\
\hline C8393Т & ATPase8 & Pro/Ser & Heteroplasmic & L8199-8218/H8627-8608 & Haelll & - \\
\hline C8478T & ATPase8 & Ser/Leu & Heteroplasmic & L8357-8381a/H8479-8503 & Trull & - \\
\hline T8551C & ATPase6/ATPase8 & Phe/Leu & Heteroplasmic & L8199-8218/H8627-8608 & $\mathrm{BspHI}$ & - \\
\hline A12026G & ND4 & lle/Val & Homoplasmic & L11798-11817/H12519-12500 & Hincll & - \\
\hline T14709C & tRNAGlu & - & Heteroplasmic & L14682-14708a/H14966-14947 & Ndel & 23 \\
\hline T14577C & ND6 & $\mathrm{Val} / \mathrm{lle}$ & Heteroplasmic & L14556-14576a/H14763-14742 & $\mathrm{Mbol}$ & - \\
\hline
\end{tabular}




\section{RESULTS}

The tRNA ${ }^{\mathrm{Leu}(\mathrm{UUR})}$, NDl, tRNA ${ }^{\mathrm{Lys}}$ and ATPase8 genes, as well as theirs surrounding regions were sequenced in 38 MIDD patients. In 31 of these, we found 38 base changes relative to the standard Cambridge sequence (13) (Table 2). Twenty-three of these substitutions are synonymous mutations, fifteen are non-synonymous

Table 2. mtDNA mutations in MIDD patients: results of direct sequencing.

\begin{tabular}{|c|c|}
\hline Patients & mtDNA mutations \\
\hline 1 & G3226C $a, e ; A 3480 G^{b}$ \\
\hline 2 & $\begin{array}{l}\text { T3396C } C^{b}, A^{3} 447 G^{b}, A^{3} 3505 G^{b}, \\
T^{b} 4218 C^{b}, \text { A8527 }^{d}, \text { T8551 }^{f}\end{array}$ \\
\hline 3 & G3226C a,e; $A 8577 G^{d}$ \\
\hline 4,5 & $\mathrm{~A} 3505 \mathrm{G}^{\mathrm{b}}$ \\
\hline 6 & G3226C a,e; G3918Ab,$A 3987 G^{b}$ \\
\hline 7 & $\mathrm{C} 3435 \mathrm{~T}^{\mathrm{b}, \mathrm{e}}, \mathrm{T} 4248 \mathrm{C}^{\mathrm{b}}$ \\
\hline 8 & $\mathrm{~A} 3447 \mathrm{G}^{\mathrm{b}}, \mathrm{T}^{2} 216 \mathrm{C}^{\mathrm{b}}$ \\
\hline 9 & 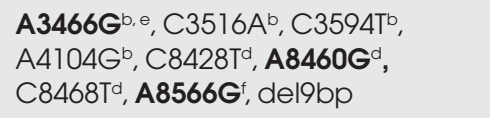 \\
\hline $10,11,12$ & A3547G ${ }^{b}$, del9bp \\
\hline 13 & 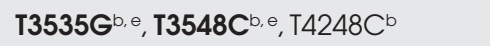 \\
\hline 14 & Т3552A ${ }^{b}, \mathbf{G 8 5 8 4 A}$ \\
\hline 15 & T3552A ${ }^{\mathrm{b}}, \mathrm{C} 4242 \mathrm{~T}^{\mathrm{b}}$ \\
\hline 16 & $\begin{array}{l}\mathrm{C}^{3594 \mathrm{~T}^{\mathrm{b}}}, \mathrm{A} 8348 \mathrm{G}^{\mathrm{c}}, \mathrm{C} 8428 \mathrm{~T}^{\mathrm{d}}, \\
\text { A8460G }^{\mathrm{d}}, \mathrm{C}^{\prime} 846 \mathrm{~T}^{\mathrm{d}}, \mathbf{A 8 5 6 6 \mathrm { G } ^ { f }} \text {, del 9bp }\end{array}$ \\
\hline 17 & $\mathrm{~A} 3672 \mathrm{G}^{\mathrm{b}}$ \\
\hline 18,19 & C3795G $\mathrm{G}^{\mathrm{b}, \mathrm{e}}, \mathrm{T} 4248 \mathrm{C}^{\mathrm{b}}$ \\
\hline 20 & G3834A \\
\hline 21 & $\mathrm{~T} 4216 \mathrm{C}^{\mathrm{b}}, \mathrm{C} 8455 \mathrm{~T}^{\mathrm{d}, \mathrm{e}}$ \\
\hline 22 & $\mathrm{~T}_{4216 C^{b}}, \mathrm{~T}^{2} 232 \mathrm{C}^{\mathrm{b}}, \mathrm{T} 404 \mathrm{C}^{\mathrm{d}}$ \\
\hline 23 & $\mathrm{C} 8393 \mathrm{~T}^{\mathrm{d}}$ \\
\hline 24 & $\mathrm{C} 8414 \mathrm{~T}^{\mathrm{d}}$ \\
\hline 25,26 & $\begin{array}{l}\text { C8428T }^{d}, \text { A8460G }^{d}, \text { C8468 }^{d} \text {; } \\
\text { A8566G }^{f} \text {, del } 9 \mathrm{bp}\end{array}$ \\
\hline 27,28 & $\mathrm{C} 8468 \mathrm{~T}^{\mathrm{d}}$ \\
\hline 29 & $\mathrm{~T} 3548 \mathrm{C}^{\mathrm{b}, \mathrm{e}}, \mathrm{C} 8478 \mathrm{~T}^{\mathrm{d}}$ \\
\hline 30,31 & Del 9bp \\
\hline
\end{tabular}

Mutations displayed in bold cause amino-acid changes. The remaining mutations are synonymous or occur in the 16S-rRNA or tRNA ${ }^{\text {Lys }}$ genes. Mutations are localized in a 16S-rRNA, 'DND1, ctRNA ${ }^{\text {Lys }}$ or dATPase8 genes, with exception of the G8584A mutation that occurs in the ATPaseb gene. ${ }^{e}$ Novel mutations. ${ }^{\dagger}$ Substituted nucleotide does not change the amino-acid in ATPase8 gene, but it changes in the overlapped ATPaseb gene. mutations and two occur in the 16S-rRNA and tRNA ${ }^{\mathrm{Lys}}$ genes. This sum exceeds the total number of mutations because two of them (A8566G and T8551C) occur in a region of overlap between the ATPase 8 and ATPase6 genes, and cause synonymous changes in the first gene and non-synonymous changes in the second gene. To our knowledge, 31 of the mutations were previously described and the remaining seven are novel mutations. By the analyses of the sequencing chromatograms, we observed four mutations in heteroplasmy (T3548C, C8393T, C8478T and T8551C), which was confirmed by PCR-RFLP analyses in polyacrilamide gels. Besides the point mutations, 9 MIDD patients presented the common 9 bp deletion at position 8272-8280 (noncoding region).

Among the 38 base-changes found within the MIDD group, those considered to be potentially pathogenic were selected to be further investigated in the "classical" type 2 DM group. Criteria to select these mutations were: 1- the mutation must not be a known neutral polymorphism; 2 - it must affect an evolutionarily conserved nucleotide; 3 - it should be heteroplasmic; 4- it must involve change between chemically different amino-acids or impair OXPHOS; and 5- it was previously reported in association with a mitochondrial disease (14). Five mutations met two or more of these criteria (T3548C, A8348G, C8393T, C8478T and $\mathrm{T} 855 \mathrm{lC}$ ). These 5 potentially pathogenic mtDNA mutations found in MIDD patients along with the 10 mtDNA mutations, already described in a possible association with type $2 \mathrm{DM}$, were then screened by PCRRFLP analyses in the total group of patients.

As the frequencies of mutations did not differ between Caucasoid- and African-Brazilian patients (data not shown), we present the results for the whole population. Overall, we found an mtDNA mutation in 24 subjects $(5.39 \%$ of the total group of patients). The following mtDNA mutations were found in 10 patients of the "classical" type 2 DM group: Cl310T (0.49\%, $\mathrm{n}=2)$, G3316A $(0.25 \%, \mathrm{n}=1)$, T3394C $(0.74 \%, \mathrm{n}=3)$, C8393T $(0.49 \%, \mathrm{n}=2), \mathrm{T} 14577 \mathrm{C}(0.25 \%, \mathrm{n}=1)$ e T14709C $(0.25 \%, \mathrm{n}=1)$. Fourteen patients with clinical characteristics of MIDD presented the following mutations: C1310T $(5.26 \%, \mathrm{n}=2)$, Al438G $(5.26 \%$, $\mathrm{n}=2)$, A3243G $(5.26 \%, \mathrm{n}=2)$, T3394C $(2.63 \%, \mathrm{n}=1)$, T3548C (5.26\%, n= 2), A8348G (2.63\%, n= 1), C8393T (2.63\%, $\mathrm{n}=1)$, C8478T $(2.63 \%, \mathrm{n}=1)$, T8551C $(2.63 \%, \mathrm{n}=1), \mathrm{Tl} 4577 \mathrm{C}(2.63 \%, \mathrm{n}=1) \mathrm{e}$ T14709C (2.63\%, n= 1). The T3271C, A8344G and Al2026G mutations were not found in any subject. In 
general, the analyzed mtDNA mutations are more frequent amongst the 38 MIDD patients than amongst 407 "classical" type 2 diabetic patients $(36.84 \%$ versus $2.45 \%$, respectively, $\mathrm{p}<0.001$ ).

Patients with and without mtDNA mutations appear to differ in respect to some clinical characteristics (Table 3). As expected, patients carrying an mtDNA mutation are younger, leaner and have lower blood glucose and C-peptide levels than patients without $\mathrm{mu}$ tations. Besides, they have an earlier age of onset when compared to other patients. We also observed a higher frequency of deafness in patients carrying $\mathrm{mtDNA} \mathrm{mu-}$ tations as compared to patients with no mutation $(58.0 \%$ versus $27.8 \%$, respectively; $\mathrm{p}=0.044)$. Additionally, a maternal history of type $2 \mathrm{DM}$ was reported by $68.0 \%$ of the patients with mtDNA mutations and by $35.5 \%$ of the patients without mutations $(\mathrm{p}=0.002)$.

\section{DISCUSSION}

In the present study we observed that approximately $5.5 \%$ of the patients with type $2 \mathrm{DM}$ present a possibly pathogenic mtDNA mutation. This number is higher when we consider only those patients with clinical characteristics suggestive of MIDD (36.8\%), suggesting the importance of $\mathrm{mtDNA}$ defects in the pathogenesis of this subtype of DM. Nonetheless, prior to attribu- ting pathogenicity to an mtDNA mutation, it should ideally fulfill some of the criteria already described in the results section (14). The T8551C, A3243G, T14577C, T14709C, C8393T and C8478T mutations were observed in heteroplasmy, alter highly conserved nucleotides and apparently result in an impaired activity of the OXPHOS (15-18), fulfilling most of the criteria defining a pathogenic mtDNA mutation.

The A3243G mutation in the tRNALeu(UUR) was detected in $0.45 \%$ of the total type $2 \mathrm{DM}$ group; this frequency being similar to the overall prevalent rate observed in other populations (6,7). Affected patients could have been undetected if the percentage of heteroplasmy was particularly low in leucocytes DNA, although this is unlikely to have happened in the present study in view of the sensitivity of the method used to detect mutant mtDNA (19). When we considered only those patients with clinical characteristics of MIDD, the frequency of the A3243G mutation increased to approximately $5 \%$. Despite the frequency being relatively low, it is important to identify patients with this mutation, since they could also have severe symptoms resulting from other mitochondrial diseases, requiring a different treatment in relation to other diabetic patients $(7,20)$. The two patients diagnosed as having the $\mathrm{A} 3243 \mathrm{G}$ mutation presented the following characteristics: diagnostic of type $2 \mathrm{DM}$ before the age of $30 ; \mathrm{BMI}<25 \mathrm{~kg} / \mathrm{m}^{2}$; neu-

Table 3. Clinical and laboratory characteristics of the type 2 diabetic group subdivided according to the presence of mtDNA mutations.

\begin{tabular}{|c|c|c|c|}
\hline Characteristics & $\begin{array}{c}\text { Patients without mtDNA } \\
\text { mutations }\end{array}$ & $\begin{array}{c}\text { Patients carrying mtDNA } \\
\text { mutations }\end{array}$ & p value ${ }^{\circ}$ \\
\hline number & 421 & 24 & - \\
\hline $\operatorname{Sex}(\% \mathrm{M})$ & 36.81 & 43.52 & 0.671 \\
\hline Age (years) & $57.5 \pm 11.8$ & $51.37 \pm 9.6$ & 0.044 \\
\hline Age at diagnosis $<40$ years (\%) & $33.44 \%$ & $53.56 \%$ & 0.042 \\
\hline $\mathrm{BMl}<25 \mathrm{~kg} / \mathrm{m}^{2}(\%)$ & $21.98 \%$ & $53.85 \%$ & 0.022 \\
\hline GhB (\%) & $7.10 \pm 1.91$ & $7.30 \pm 1.90$ & 0.602 \\
\hline Blood glucose $(\mathrm{mmol} / \mathrm{l})$ & $9.82 \pm 4.22$ & $6.88 \pm 1.59$ & 0.001 \\
\hline Total cholesterol (mmol/l) & $5.64 \pm 1.30$ & $5.45 \pm 1.88$ & 0.828 \\
\hline Triglycerides (mmol/l) & $1.65(0.29-16.60)$ & $1.38(0.49-3.59)$ & 0.238 \\
\hline Serum creatinine $(\mu \mathrm{mol} / \mathrm{l})$ & $83.10(35.41-733.72)$ & $79.64(53.0-141.46)$ & 0.664 \\
\hline Hypertension (\%) & 61.73 & 45.51 & 0.196 \\
\hline C-peptide (nmol/l) & $0.75(0.03-2.63)$ & $0.34(0.07-1.96)$ & 0.019 \\
\hline Retinopathy (\%) & 46.92 & 38.11 & 0.577 \\
\hline Nephropathy (\%) & 31.91 & 45.52 & 0.352 \\
\hline Distal sensory neuropathy (\%) & 47.19 & 50.01 & 0.894 \\
\hline Insulin treatment (\%) & 37.13 & 46.28 & 0.512 \\
\hline
\end{tabular}

Data are shown as means \pm SD, percentage or geometric mean (range); a $\mathrm{p}$ for comparisons between patients with or without mtDNA mutations. 
rosensorial deafness; C-peptide levels next to zero; insulin treatment; and presence of proliferative retinopathy and ischemic cardiomyopathy.

The T8551C mutation in the overlapping region in the ATPase 8 and ATPase 6 genes had already been described in a Siberian family with LHON syndrome (15). We observed this mutation in only one patient belonging to the MIDD group. This patient had type 2 DM diagnosed before the age of 40 and presented neurosensorial deafness and cardiomyopathy. The T14577C mutation in the NADH-dehydrogenase 6 (ND6) gene was first identified in $1.2 \%$ of a sample of Japanese type 2 diabetic patients, not being observed in any subject of the control group (17). We found this mutation in a patient with "classical" type $2 \mathrm{DM}$ and also in a patient within the MIDD group. The T14709C mutation in the tRNA ${ }^{\text {Glu }}$ gene was reported in type 2 diabetic families segregating with neurosensorial deafness, myopathy with ragged red fibers, encephalomyopathy and/or infantile cardiomyopathy $(18,21-23)$. We observed this mutation in a patient of the "classical" type $2 \mathrm{DM}$ group and in a patient of the MIDD group. This last patient also presented ischemic cardiomyopathy, nonproliferative diabetic retinopathy and cataract. The C8393T mutation in the ATPase8 gene was previously described in subjects with LHON syndrome or neurosensorial deafness $(24,25)$. This mutation was observed in two "classical" type 2 diabetic patients and in one patient of the MIDD group.

The T3548C mutation in the NDl gene was not found at MITOMAP and mtDB databases, and thus is a novel heteroplasmic mutation. Two patients belonging to the MIDD group presented this mutation, one of them also presenting the C8478T mutation in the ATPase8 gene. Obviously, the functional significance of these two mutations to the development of MIDD requires further investigation.

On the other hand, unlike many pathogenic mutations, the C1310T, Al438G, G3316A, T3394C and A8348G mutations are homoplasmics, which are generally considered to reflect neutral variation. However, some homoplasmic mutations, including the T3394C mutation, have been reported as secondary mutations involved in the pathogenesis of LHON syndrome (26). Such secondary mutations are not sufficient to induce the diseases, but influence the severity of disease expression in the presence of some modifiers (26).

The C1310T and Al438G mutations in the rRNAl2S gene have been described in $2.8 \%$ and $2.4 \%$ of a Japanese type 2 diabetic group, respectively (27), and also in some patients with Parkinson's disease (28). The
G3316A and T3394C mutations in the NDl gene were reported as being associated with type $2 \mathrm{DM}$ in some populations (29-34); however, some authors did not observe any significant differences between the frequencies of these mutations among diabetic patients and healthy subjects, suggesting that these mutation are only neutral polymorphisms $(19,35,36)$. The A8348G mutation in the tRNA ${ }^{\text {Lys }}$ gene has never been reported in diabetic patients, but was previously reported in association with several changes in mitochondria of cardiomyocytes in patients presenting hypertrophic cardiomyopathy (37). In this study, the A8348G mutation was observed in a patient with characteristics of MIDD and presenting dilated cardiomyopathy, proliferative diabetic retinopathy, peripheral neuropathy and a severe clinical depression, suggesting that this mutation probably cause an OXPHOS dysfunction.

As expected, we also showed that type 2 diabetic patients with mtDNA mutations are younger, leaner, present lower blood glucose and C-peptide levels and a higher frequency of neurosensorial deafness than patients without any mtDNA mutation. In addition, patients with mtDNA mutations more frequently related a maternal history of type $2 \mathrm{DM}$ when compared to the group without mtDNA mutations. These results indicate that many of the mutations analyzed in our study may cause a phenotype very similar to that presented by MIDD patients described in other studies $(6,7,38)$.

In conclusion, this study demonstrates the high overall frequency of $12 \mathrm{mtDNA}$ mutations in type 2 diabetic patients with clinical characteristics of MIDD. So far, MIDD have been mostly associated with the A3243G mutation, despite other, less frequent $\mathrm{mtD}$ NA mutations have been also observed. In our sample of type 2 diabetic patients, however, we found the A3243G mutation in a frequency similar to that observed for other mutations, suggesting that other possibly pathogenic mtDNA mutations also can play an important role for MIDD development. Detailed studies will have to be performed in patients carrying these mutations and their relatives, in order to define the importance of the observed mtDNA defects to the clinical characteristic of MIDD. The identification of patients presenting MIDD will be very important, since these patients could have some severe symptoms that could be wrongly attributed only to the presence of DM, and thus, they might require a different treatment in relation to other diabetic patients.

Acknowledments. This study was supported by grants from Conselho Nacional de Desenvolvimento Científico e Tecnológico (CNPq); Programa de Apoio a Núcleos de Excelência; and 
Financiadora de Estudos e Projetos. We thank Dr. Kátia E. P. Souto and Dr. Balduino Tschiedel for kindly supplying part of the sample; and Prof. Dr. Nelson J.R. Fagundes for the critical comments on this manuscript. We stated that there is no potential conflict of interest of any author, and that our report does not imply in any sort of conflict of interest that would prejudice the impartiality of this scientific work.

\section{REFERENCES}

1. Alcolado JC, Laji K, Gill-Randall R. Maternal transmission of diabetes. Diabet Med. 2002:19:89-98.

2. Crispim D, Canani LH, Gross JL, Tschiedel B, Souto KE, Roisenberg I. Familial history of type 2 diabetes in patients from Southern Brazil and its influence on the clinical characteristics of this disease. Arq Bras Endocrinol Metab. 2006:50:862-8.

3. Kadowaki T, Kadowaki H, Mori Y, Tobe K, Sakuta R, Suzuki Y, et al. A subtype of diabetes mellitus associated with a mutation of mitochondrial DNA. N Engl J Med. 1994:330:962-8.

4. Goto Y, Nonaka I, Horai S. A mutation in tRNA(Leu)(UUR) gene associated with the MELAS subgroup of mitochondrial encephalomyopathies. Nature. 1990:348:651-3.

5. van den Ouweland JMW, Lemkes HHPJ, Ruitenbeek W, Sandkuijl LA, de Vijlder MF, Struyvenberg PAA, et al. Mutation in mitochondrial tRNALeu(UUR) gene in a large pedigree with maternally transmitted type II diabetes mellitus and deafness. Nat Genet. 1992:1:368-71.

6. Maassen JA, Tafrechi JRS, Janssen GMC, Raap AK, Lemkes $\mathrm{HH}$, 't-Hart LM. New insights in the molecular pathogenesis of the maternally inherited diabetes and deafness syndrome. Endocrinol Metab North Am. 2006:35:385-96.

7. Murphy R, Turnbull DM, Walker M, Hattersley AT. Clinical features, diagnosis and management of maternally inherited diabetes and deafness (MIDD) associated with the $3243 \mathrm{~A}>\mathrm{G}$ mitochondrial point mutation. Diabet Med. 2007:25:383-99.

8. Lamson DW, Plaza SM. Mitochondrial factors in the pathogenesis of diabetes: a hypothesis for treatment. Altern Med Rev. 2002:7:94-111.

9. WHO Study Group: Diabetes Mellitus. Technical Report Series 727. Geneva: World Health Organization, 1985.

10. Choo-Kang ATW, Lynn S, Taylor GA, Daly ME, Sihota SS, Wardell TM et al. Defining the importance of mitochondrial gene defects in maternally inherited diabetes by sequencing the entire mitochondrial genome. Diabetes. 2002:51:2317-20.

11. MITOMAP: A Human Mitochondrial Genome Database. Available from: http://www.mitomap.org, 2008.

12. Ingman M, Gyllensten U. mtDB: Human Mitochondrial Genome Database, a resource for population genetics and medical sciences. Nucleic Acids Res. 2006:34:749-51.

13. Anderson S, Bankier AT, Barrell BG, De Bruijn MHL, Coulson $A R$, Drouin $J$ et al. Sequence and organization of the human mitochondrial genome. Nature. 1981:290:457-65.

14. DiMauro S, Schon EA. Mitochondrial DNA mutations in human disease. Am J Med Genet. 2001:106:18-26.

15. Brown MD, Zhadanov S, Allen JC, Hosseini S, Newman NJ, Atamonov $V V$ et al. Novel mtDNA mutations and oxidative phosphorylation dysfunction in Russian LHON families. Hum Genet. 2001:109:33-9.

16. Chomyn A, Martinuzzi A, Yoneda M. MELAS mutation in mtDNA binding site for transcription termination factor causes de- fects in protein synthesis and in respiration but no change in levels of upstream and downstream mature transcripts. Proc Natl Acad Sci. 1992:89:4221-5.

17. Tawata M, Hayashi J-I, Isobe K, Ohkubo E, Ohtaka M, Chen J et al. A new mitochondrial DNA mutation at $14577 \mathrm{~T} / \mathrm{C}$ is probably a major pathogenic mutation for maternally inherited type 2 diabetes. Diabetes. 2000:49:1269-72.

18. Hanna MG, Nelson I, Sweeney MG, Cooper JM, Watkins PJ, Morgan-Hughes JA, et al. Congenital encephalomyopathy and adult-onset myopathy and diabetes mellitus: different phenotypic associations of a new heteroplasmic mtDNA tRNA glutamic acid mutation. Am J Hum Genet. 1995:56:1026-33.

19. Crispim D, Tschiedel B, Souto KEP, Roisenberg I. Prevalence of three mitochondrial DNA mutations in type 2 diabetic patients from Southern Brazil. Clin Endocrinol. 2002:57:141-2.

20. Maassen JA, 't-Hart LM, van Essen E, Heine RJ, Nijpels G, Tafrechi RSJ, et al. Mitochondrial diabetes: Molecular mechanisms and clinical presentation. Diabetes. 2004:53:103-9.

21. Hao H, Bonilla E, Manfredi G, DiMauro, Moraes CT. Segregation patterns of a novel mutation in the mitochondrial tRNA glutamic acid gene associated with myopathy and diabetes mellitus. Am J Hum Genet. 1995:56:1017-25.

22. Vialettes $B H$, Paquis-Flucklinger $V$, Pelissier JF, Bendahan $D$, Narbonne H, Silvestre-Aillaud $\mathrm{P}$, et al. Phenotypic expression of diabetes secondary to a $\mathrm{T} 14709 \mathrm{C}$ mutation of mitochondrial DNA. Diabetes Care. 1997:20:1731-7.

23. Perucca-Lostalen D, Narbonne H, Hernandez JB, Staccini $P$, Saunieres A, Paquis-Flucklinger $V$, et al. Mitochondrial DNA variants in patients with maternally inherited diabetes and deafness syndrome. Biochem Biophys Res Commun. 2000:277: 771-5.

24. Povalko N, Zakharova E, Rudenskaia G, Akita Y, Hirata K, Toyojiro $M$, et al. A new sequence variant in mitochondrial DNA associated with high penetrance of Russian Leber hereditary optic neuropathy. Mitochondrion. 2005:5:194-9.

25. Lehtonen MS, Moilanen JS, Majamaa K. Increased variation in mtDNA in patients with familial sensorineural hearing impairment. Hum Genet. 2003:113:220-7.

26. Carelli V, Giordano C, d'Amati G. Pathogenic expression of homoplasmic mtDNA mutations needs a complex nuclear-mitochondrial interaction. Trends Genet. 2003:19:257-62.

27. Tawata M, Ohtaka M, Iwase E, Ikegishi Y, Aida K, Onaya T. New mitochondrial DNA homoplasmic mutations associated with Japanese patients with type 2 diabetes. Diabetes. 1998: 47:276-7.

28. Ikebi S-I, Tanaka M, Ozawa T. Point mutations of mitochondrial genome in Parkinson's disease. Mol Brain Res. 1995:28:281-95.

29. Nagakawa $Y$, Ikegami $H$, Yamato $M$, Takekawa $K$, Fujisawa T, Hamada $Y$, et al. A new mitochondrial DNA mutation associated with non-insulin-dependent diabetes mellitus. Biochem Biophys Res Commun. 1995:209:664-8.

30. Fukuda M, Nakano S, Imaizumi N, Kitasawa M, Nishisawa M, Kigoshi T, et al. Mitochondrial DNA mutations are associated with both decreased insulin secretion and advanced microvascular complications in Japanese Diabetic subjects. J Diabetes Complications. 1999:13:277-83.

31. Yu P, Yu DM, Liu DM, Wang K, Tang XZ. Relationship between mutations of mitochondrial DNA ND1 gene and type 2 diabetes. Chin Med. J 2004:117:985-9.

32. Hirai M, Suzuki S, Onoda M, Hinokio Y, Ai L, Hirai A, et al. Mitochondrial DNA 3394 mutations in the NADH-dehydrogenase subunit 1 associated with non-insulin-dependent diabetes mellitus. Biochem Byophys Res Commun. 1996:219:951-5. 
33. Liu SM, Zhou X, Zheng F, Li X, Liu F, Zhang HM, et al. Novel mutations found in mitochondrial diabetes in Chinese Han population. Diabetes Res Clin Pract. 2007:76(3):425-35.

34. Tang DL, Zhou X, Li X, Zhao L, Liu F. Variation of mitochondrial gene and the association with type 2 diabetes mellitus in a Chinese population. Diabetes Res Clin Pract. 2006:73(1):77-82.

35. Lam C-W, Yang T, Tsang M-W, Pang C-P. Homoplasmic 3316 G/A in the ND1 gene of the mitochondrial genome: a pathogenic mutation or a neutral polymorphism? J Med Genet. 2001:38. [Available from http://www.jmedgenet.com/cgi/content/full/38/3/e10].

36. Ohkubo K, Yamano A, Nagashima M, Mory Y, Anzai K, Akeki Y, et al. Mitochondrial gene mutations in the tRNALeu(UUR) region and diabetes: prevalence and clinical phenotypes in Japan. Clin Chem. 2001:47:1641-8.

37. Terasaki F, Tanaka M, Kawamura K, Kanzaki Y, Okabe M, Hayashi T, et al. A case of cardiomyopathy showing progression from the hypertrophic to the dilated form - association of $\mathrm{mt8348A} / \mathrm{G}$ mutation in the mitochondrial tRNA ${ }^{\text {Lys }}$ gene with severe ultra structural alterations of mitochondria in cardiomyocytes. Japan Circ. J 2001:65:691-4.

38. Suzuki S, Oka Y, Kadowaki T, Kanatsuka A, Kuzuya T, Kobayashi M, Sanke T, et al. The Research Committee for Specific Types of Diabetes Mellitus with Gene Mutations of the Japan Diabetes Sociaty: Clinical features of diabetes mellitus with the mitochondrial DNA 3243 (A-G) mutation in Japanese: maternal inheritance and mitochondria-related complications. Diab Res Clin Pract. 2003:59:207-17.

\section{Correspondence to:}

Daisy Crispim

Serviço de Endocrinologia, Hospital de Clínicas de Porto Alegre.

Rua Ramiro Barcelos 2350; prédio 12; $4^{\circ}$ andar.

90035-003 Porto Alegre, RS, Brazil.

E-mail: daisy_crispim@hotmail.com 